\title{
Contributions of Nonvolatile Phytochemicals to Nutrition and Flavor
}

\author{
P. Perkins-Veazie and J.K. Collins
}

\begin{abstract}
AdDitional INDEX wORDs. ascorbic acid, dietary fiber, folate, organoleptic, phytoestrogens, polyphenolics

Summary. Small fruit are rich in several types of phytochemicals, vitamins, and minerals. These compounds have health functional properties that may protect humans from cardiovascular disease and certain cancers. Several of these phytochemicals, such as dietary fiber, anthocyanins, and polyphenolics, also contribute to small fruit quality. Other components contribute to appearance and taste. Nonvolatile organic acids contribute to the perceived sourness of small fruit and changes in levels can alter visual color by affecting cellular $\mathrm{pH}$ and anthocyanin structure. The soluble sugars glucose, fructose, and sucrose contribute directly to the perceived sweetness of the fruit and provide carbohydrates for other metabolic functions such as phenolic and ascorbic acid synthesis.
\end{abstract}

S mall fruit cover a range of flavors, from sour to sweet to ambrosial. Perhaps most noted for flavor are strawberries (Fragaria $\times$ ananassa) and raspberries (Rubus idaeus), which have powerful taste and aromatic notes. Other small fruit can range from primarily sour or astringent, such as cranberries (Vaccinium macrocarpon), to sweet with little character, such as many table grape (Vitis vinifera) varieties. The nonvolatile acids and sugars potentiate the flavor of volatile aroma compounds that impart the flavor notes associated with each fruit. Tannins provide the astringent or bitter notes often found in immature berries and the water soluble pigments of ripe fruit. Fruit texture depends on the amount of soluble and insoluble fiber, made up of pectins, cellulose, and hemicellulose. Until recently, small fruit were primarily perceived as dessert-type products, or for processing into juices and wines. The discovery of relatively high levels of anticancer compounds such as the phenolic compound, ellagic acid, in small fruit (Daniel et al., 1989), and the finding that increased intake of fruit and vegetables reduced the incidence of cancer and coronary heart disease (Block et al., 1992; Kamei et al., 1995; Steinmetz and Potter, 1996) has sparked great interest in the consumption of small fruit for their health benefits. The objective of this review is to present the relationship between the health promoting phytochemicals and quality in small fruit.

Mention of trade names or commercial products in this article is solely for the purpose of providing specific information and does not imply recommendation or endorsement by the U.S. Department of Agriculture. All programs and services of the U.S. Department of Agriculture are offered on a nondiscriminatory basis without regard to race, color, national origin, religion, sex, age, marital status, or handicap. The article cited was prepared by a USDA employee as part of his/her official duties. Copyright protection under U.S. copyright law is not available for such works. Accordingly, there is no copyright to transfer. The fact that the private publication in which the article appears is itself copyrighted does not affect the material of the U.S. Government, which can be freely reproduced by the public. 


\section{Phytochemicals from nonvolatile sources in small fruit}

Functional foods contain phytochemicals, defined as the nutritive or nonnutritive compounds found in plants that are associated with reduced disease risk. Because of the nutritive properties of fruit, the United States Department of Agriculture (2000) and the American Heart Association (2000) recommend three to five servings of fruit per day. The most commonly found nonvolatile phytochemicals in small fruit include ascorbic acid (vitamin C), calcium, potassium, dietary fiber, folic acid, phytoestrogens, and phenolic compounds (including anthocyanins and tannins) (Tables 1 and 2 ). A list of the reported effects of these phytochemicals on human health is given in Table 3. Even though a single phytochemical has health properties, small fruit are comprised of a mixture of phyto-chemicals, some in minute amounts, which may result in a more powerful and synergistic effect on disease prevention than larger amounts of one phytochemical.

\section{Vitamin C}

Vitamin C serves as a cofactor for many enzymes controlling functions in the human body and is a powerful water soluble antioxidant that prevents free radical damage to cells (Buettner, 1993). Vitamin C may also be used by the body to regenerate another important lipid soluble antioxidant, $\alpha$-tocopherol (vitamin E) (Jacob, 1995). Increased intake of vitamin $\mathrm{C}$ is correlated with a reduction in risks of stroke (Gey et al., 1993) and certain cancers (Byers and Guerrero, 1995). Most small fruit contain moderate to high amounts of vitamin C (Table 1 ). Ascorbic and dehydroascorbic acid are the two active forms of vitamin $\mathrm{C}$. The USDA-recommended dietary intake of vitamin $\mathrm{C}$ was increased recently from $60 \mathrm{mg} \cdot \mathrm{d}^{-1}\left(2.1 \times 10^{-3} \mathrm{oz}\right)$ to 75 $\mathrm{mg} \cdot \mathrm{d}^{-1}\left(2.6 \times 10^{-3} \mathrm{Oz}\right)$ for women and $90 \mathrm{mg} \cdot \mathrm{d}^{-1}$ in men $\left(3.2 \times 10^{-3} \mathrm{Oz}\right)$, with an additional $35 \mathrm{mg} \cdot \mathrm{d}^{-1}\left(1.2 \times 10^{-3} \mathrm{oz}\right)$ recommended for smokers (Food and Nutrition Board, 2000). Horticultural studies involving small fruit often overlook the analysis of this important vitamin, although postharvest studies have shown losses of this vitamin in small fruit held for short durations at temperatures greater than $5{ }^{\circ} \mathrm{C}\left(41^{\circ} \mathrm{F}\right)$ (Lee and Kader, 2000).

\section{Folate}

Folate (folic acid) a B-vitamin found in fruit, vegetables and grains, acts as a coenzyme in the body and may lower homocysteine levels (Tucker et al., 1996). Lower homocysteine levels are reported to reduce cardiovascu- lar disease risk (Brouwer et al., 1999). An inadequate intake of folate by pregnant women increases the risk of neural tube defects in babies (Brouwer et al., 1999; Czeizel and Dudas, 1992). The Recommended Dietary Intake is $400 \mu \mathrm{g} \cdot \mathrm{d}^{-1}\left(1.4 \times 10^{-5} \mathrm{oz}\right)$ of dietary folate equivalent (Food and Nutrition Board, 2000). Small fruit especially blackberries, strawberries, and raspberries, provide a slight to moderate ( $5 \%$ to $10 \%$ ) source of dietary folate (Table 1).

\section{Dietary fiber}

Small fruit are a good source of dietary fiber, primarily pectin. Dietary fiber is defined as plant material that is resistant to digestive enzymes in humans and is divided into two groups based upon solubility in water (Brown et al., 1999). Insoluble fibers consist of cellulose and lignin and some hemicellulose fibers. Soluble fibers include some hemicelluloses, gums, mucilages and pectins, which are natural gel formers. Soluble fibers, including pectins, have been reported to lower cholesterol levels in humans, although the results have varied as to the extent of the cholesterol lowering properties (Brown et al., 1999). The mechanisms involved in this biological action are not yet determined; one hypothesized action is that cholesterol and fatty acid excretion is increased with a high in-

Table 1. Nutrient composition of calories, dietary fiber, calcium, potassium, vitamin $C$ and foliate of small fruit on a per cup basis (USDA, ARS, 2001).

\begin{tabular}{|c|c|c|c|c|c|c|c|}
\hline \multirow[b]{2}{*}{ Fruit } & \multirow[b]{2}{*}{$\begin{array}{l}1 \operatorname{cup}_{(g)^{z}} w t \\
\end{array}$} & \multirow[b]{2}{*}{$\begin{array}{l}\text { Calories } \\
(\times 1000)^{\mathrm{y}}\end{array}$} & \multicolumn{5}{|c|}{ Nutrient composition } \\
\hline & & & $\begin{array}{c}\text { Dietary fiber } \\
(\mathbf{g})\end{array}$ & $\begin{array}{c}\text { Calcium } \\
(\mathrm{mg})\end{array}$ & $\begin{array}{l}\text { Potassium } \\
\text { (mg) }\end{array}$ & $\begin{array}{c}\text { Vitamin C } \\
\text { (mg) }\end{array}$ & $\begin{array}{c}\text { Folate } \\
(\mu \mathrm{g})\end{array}$ \\
\hline Blueberry (Vaccinium sp.) & 145 & 81.2 & 3.9 & 8.7 & 129.1 & 18.9 & 8.7 \\
\hline Boysenberries, canned (Rubus sp.) & 132 & 66.0 & 5.1 & 35.6 & 183.4 & 4.1 & 83.6 \\
\hline Cranberry (Vaccinium macrocarpon) & 110 & 53.9 & 4.6 & 7.7 & 78.1 & 14.9 & 2.2 \\
\hline Elderberries (Sambucus canadensis) & 145 & 105.9 & 10.2 & 55.1 & 406.0 & 52.2 & 8.7 \\
\hline Loganberries (Rubus sp.) & 147 & 80.9 & 7.2 & 38.2 & 213.2 & 22.5 & 37.8 \\
\hline Raspberry (Rubus idaeus) & 123 & 60.3 & 8.4 & 27.1 & 187.0 & 30.8 & 32.0 \\
\hline Strawberry (Fragaria ×ananassa) & 152 & 45.6 & 3.5 & 21.3 & 252.3 & 86.2 & 27.4 \\
\hline Table grape (Vitis vinifera) & 160 & 113.6 & 1.6 & 17.6 & 296.0 & 17.3 & 6.4 \\
\hline Women & -- & 2000 & 25 & $1000-1300$ & 3500 & $75^{z}$ & 400 \\
\hline
\end{tabular}

${ }^{2} 28.35 \mathrm{~g}=2.835 \times 10^{4} \mathrm{mg}=2.835 \times 10^{7} \mu \mathrm{g}=1.0 \mathrm{oz}$

y 1000 calories $=4.19 \mathrm{~kJ}$.

${ }^{x}$ Recommended that smokers take in an additional $35 \mathrm{mg} \cdot \mathrm{d}^{-1}$ of vitamin C. 
take of soluble fiber. Another action may be that the mere replacement of cholesterol-laden and fatty foods with that of fiber-rich foods in the diet is responsible for the reduction in cholesterol levels (Lampe, 1999). Dietary fiber from foods also seems to be protective against colon cancer (Howe et al., 1992). Another benefit of dietary fiber is in weight maintenance; it may improve satiety and slow the gastric emptying rate resulting in a reduction in caloric intake (Anderson et al., 1994). The USDA currently recommends 25 $\mathrm{g} \cdot \mathrm{d}^{-1}(0.88 \mathrm{oz})$ intake for dietary fiber (USDA, 2000).

\section{Minerals}

Small fruit crops are often supplemented with minerals to enhance yield, quality and fruit size. Minerals absorbed by the plant and translocated to the fruit impact the fruit nutritive value. The minerals such as potassium and calcium contribute directly to the structural and cellular integrity of the small fruit. Excessive potassium uptake during production is often associated with soft and poorly colored fruit, while addition of calcium often results in firmer fruit. Small fruit are a good source of potassium and a fair source of calcium (Table 1 ). In humans, potassium is needed for acidbase balance, osmotic equilibrium, and neuromuscular activity (Krause and Mahan, 1984). Adequate potassium intake may lower blood pressure, reduce the risk of stroke, and prevent kidney stone formation (Ettinger et al, 1997; Sacks et al., 1998). The USDA recommended dietary intake for potassium is $3,500 \mathrm{mg} \cdot \mathrm{d}^{-1}(0.12$ oz) (Food and Nutrition Board, 2000). Calcium helps maintain the structure of bones and teeth, and is needed for muscle contractions and enzymatic activity. Adequate calcium intake is also associated with a reduction in risk for hypertension and colorectal cancer (Hyman et al., 1998). The recommended dietary intake for calcium is 1000 to $1300 \mathrm{mg} \cdot \mathrm{d}^{-1}\left(3.5 \times 10^{-2}\right.$ to 4.5 $\left.\times 10^{-2} \mathrm{oz}\right)$, and is dependent upon age (Food and Nutrition Board, 2000).

\section{Phytoestrogens}

Lignan is a phytoestrogen that has only recently been reported in small fruit (Mazur, 1998). Phytoestrogens may be protective against osteoporosis, cardiovascular disease, and hormone-dependent cancers by competing with estrogen for binding sites (Bingham et al., 1998). Very little research has been conducted on phytoestrogens in small fruit. A recent study on human intake reported that relatively high amounts of plant lignan were utilized from strawberry fruit (Mazur et al., 2000). Other small fruit including brambles ( Rubus sp.), lingonberries (Vitis idaea), cranberries, red raspberries, blackcurrant (Ribesnigrum), and redcurrant (Ribes rubrum) also contain appreciable amounts of secoisolariciresinol, a plant lignan (Mazur, 1998).

\section{Phenolics}

Small fruit are a good source of phenolic compounds, comprised primarily of anthocyanins, proanthocyanins, flavonols, flavan-3-ols and phenolic acids (Table 4) (Kalt et al., 2001). Each category of phenolic compounds have different biological properties in humans. Some of the health properties attributed to these compounds include reduced risk of cardiovascular disease (by reducing platelet aggregation and oxidation of low density lipoproteins in the blood (LDL)) and certain cancers (Keevil et al., 2000). One phenolic acid that has been intensely researched medically is ellagic acid (Maas et al., 1990). Both strawberries and raspberries are good sources of this compound. Of 10 phenolics investigated for antioxidant protection against LDL oxidation, catechin, a flavan-3-ol, had the greatest antioxidant activity (Teissedre et al, 1996). Other phenolic compounds also had strong activity and were reported in order of activity as follows: catechin $>$ myrecitin $\approx$ epicatechin $\approx$ gallic acid and $>$ quercetin $\approx$ caffeic acid $\approx$ rutin $>$ ellagic acid $\approx$ cyanidin $\approx$ sinapic acid (Teissedre et al, 1996). The oxygen radical absorption capacity assay (ORAC) has also been used to identify foods with high antioxidant values, and these foods typically contain high levels of phenolic compounds (Table 2). Small fruit contain several types of these phenolics, with anthocyanins and phenolic acids present in the greatest

Table 2. Total anthocyanin, flavanoid (phenolic) composition and a measure of antioxidant capacity [oxygen radical absorbance capacity (ORAC)] of small fruit. Table data are from the following publications: Ballinger et al., 1974; Costantino et al., 1992; Deighton et al., 2000; Fuleki and Babjak, 1986; Jiao and Wang, 2000; Kalt et al., 1999; Mazza and Miniati 1993; Meyer et al., 1997; Prior et al., 1998; Wang and Stretch, 2001; Wang et al., 1996.

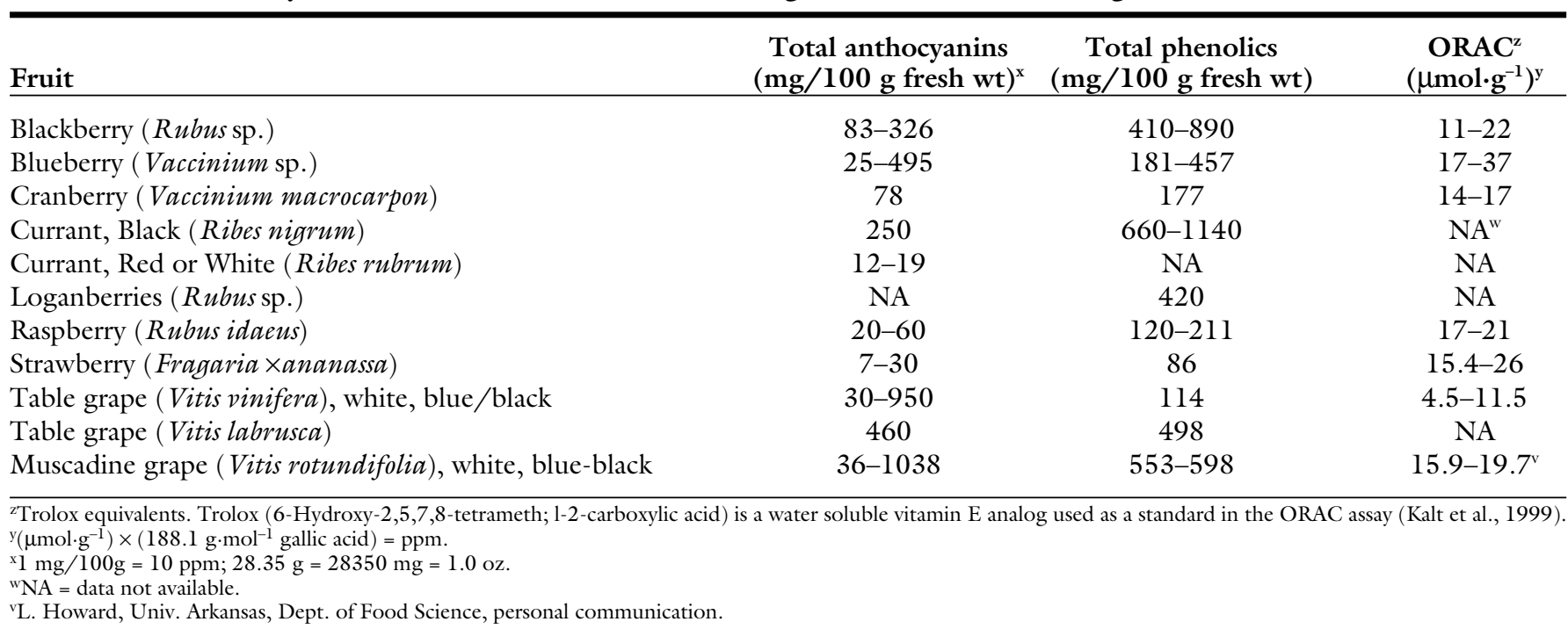


Table 3. Reported health properties of compounds found in small fruit that comprise at least $5 \%$ of recommended daily intake (RDI) on a per serving basis.

\begin{tabular}{|c|c|c|}
\hline Compound & Activities & Reference \\
\hline Folic acid & $\begin{array}{l}\text { Helps prevent neural tube defects } \\
\text { Helps regulate homocysteine and may prevent heart disease }\end{array}$ & $\begin{array}{l}\text { Czeizel and Dudas, } 1992 \\
\text { Brouwer et al., 1999; Tucker et al., } 1996\end{array}$ \\
\hline Potassium & $\begin{array}{l}\text { Lowers high blood pressure and risk of stroke } \\
\text { Prevents osteoporosis } \\
\text { Prevents kidney stone formation }\end{array}$ & $\begin{array}{l}\text { Sacks et al., 1998; Young et al., } 1995 \\
\text { Tucker et al., } 1999 \\
\text { Ettinger et al., } 1997\end{array}$ \\
\hline Phytoestrogens & $\begin{array}{l}\text { May protect against cardiovascular disease, osteoporosis, } \\
\text { and some cancers }\end{array}$ & Bingham et al., 1998 \\
\hline $\begin{array}{l}\text { Phenolics (resveratrol, } \\
\text { proanthocyanidins, } \\
\text { quercetin, } \\
\text { flavonoids, } \\
\text { anthocyanins) }\end{array}$ & $\begin{array}{l}\text { Act as antioxidants to prevent cancer initiation } \\
\text { Lowers low density lipoprotein formation to prevent heart } \\
\text { attacks, and stroke }\end{array}$ & $\begin{array}{l}\text { Igarashi and Inagaki, 1991; Smith et al., } 2000 \\
\text { Lotito and Fraga, 2000; Hertog et al., 1993; } \\
\text { Keevil et al., } 2000\end{array}$ \\
\hline
\end{tabular}

amounts (Table 2). One synergistic effect reported in antioxidant studies is that anthocyanin compounds and organic acids are protective of vitamin C (Miller and Rice-Evans, 1997). Currently, there are no recommended dietary intakes for phenolics.

\section{Quality of small fruit}

In addition to contributing to the health properties of foods, the anthocyanins provide the predominant color in most small fruit. Very small amounts of carotenoids ( $\alpha$-carotene, $\beta$-carotene, xanthophylls) are also present (Green, 1971). Early in development, small fruit are often green or greenish-red. During ripening, chlorophyll degrades, carotenoid content increases slightly, and anthocyanins increase greatly, paralleling sugar accumulation and the decline of organic acids (Woodward, 1972; Cheng and Breen, 1991). Anthocyanin pigments are affected directly and indirectly by changes in acids and sugars. For instance, attachment of specific glycosides to flavonoids creates specific anthocyanins, and increases or decreases in $\mathrm{pH}$ shift the flavyium ion concentration, affecting visual color. Accumulation of antho- cyanins and subsequent color formation in fruit can be modulated with increased exposure to UV and/or white light or addition of sucrose, glucose, or fructose (Pirie and Mullins, 1976; Sato et al., 1996). Cool night temperatures are often associated with increased color formation in small fruit. In grapes, anthocyanin accumulation in response to day/night temperature appears to depend on the predominant pigment of the variety (Pirie and Mullins, 1976).

Apart from varietal influences, ripeness at harvest is the largest contributing factor to quality. Small fruit rely on imported sugars to increase sweetness. Little or no starch is present in ripe or partially ripe fruit and thus harvested fruit must use sugars, acids, or lipids for respiration and other metabolic processes after harvest. Color development (anthocyanin synthesis) and sweetness are affected by the amount and type of available sugars (Pirie and Mullins, 1976). Sugar metabolism is necessary for the synthesis of some aromatic volatile compounds, such as the furanones that give the strawberry its characteristic flavor (Slaughter, 1999). Tannins, such as catechin and proanthocyandins, are present in immature fruit as water soluble compounds and impart astringent taste qualities (Ozawa et al., 1987).

As small fruit ripen, the soluble sugars fructose, glucose and sucrose generally increase while nonvolatile organic acids decrease. Often, an estimate of sugar content is obtained by using a refractometer to measure the percentage of total soluble solids (TSS) or soluble solids content (SSC). While sucrose and reducing sugars make up the bulk of SSC, organic acids and solubilized cell wall material also contribute to SSC.

The predominant nonvolatile organic acids found in small fruit are citric, malic, and tartaric. In blackberries ( $R$ ubus sp.), quantities of isocitric acid can be as high as citric for some varieties (Fan-Chiang, 1999). Tartaric acid is found in appreciable amounts only in grape, and is dependent on the variety (Kliewer et al., 1967). Other acids, such as succinic, shikimic and fumaric, occur in some small fruit although in minute amounts. The nonvolatile organic acids are usually found as free acids or salts, but can occur as 
Table 4. Compounds that make up the total flavonoids (proanthocyanidins, flavan-3-ols, flavonols, phenolic acids, anthocyanins) in small fruit (adapted from Kalt et al., 2001).

\begin{tabular}{|c|c|c|c|c|c|}
\hline \multirow[b]{2}{*}{ Proanthocyanindins } & \multirow[b]{2}{*}{ Flavan-3-ols } & \multirow[b]{2}{*}{ Flavonols } & \multicolumn{2}{|c|}{ Phenolic acids } & \multirow{2}{*}{$\begin{array}{c}\text { Anthocyanins } \\
\text { (aglycones) }\end{array}$} \\
\hline & & & Hydroxycinnamic & Hydroxybenzoic & \\
\hline Gallocatechin & Catechin & Kaempferol & p-Coumaric & p-Hydroxybenzoic & Delphinidin \\
\hline & & Myricetin & Ferulic & Ellagic & Petunidin \\
\hline & & & Chlorogenic acid & & Malvidin \\
\hline & & & & & Peonidin \\
\hline
\end{tabular}

crystals when in high concentrations, such as calcium oxalate or potassium bitartrate (Ulrich, 1970). Titratable acidity is a measure of the free acids, while total acidity is the sum of all acids, free or combined (usually with cations) (Ulrich, 1970). Titratable acidity is generally measured by titrating the diluted fruit sample (juice or $\mathrm{pu}^{-}$ ree) to a $\mathrm{pH}$ endpoint of 8.1.with 0.1 $\mathrm{N}$ sodium hydroxide. While most small fruit do not have USDA grading standards for sugar and/or acid content, table grapes must have a soluble solids range of $14 \%$ to $17.5 \%$ and/or a soluble solids/acids ratio of $>20$ to be marketed (Kader, 1992).

\section{Organoleptic characteristics of small fruit}

Sugars, organic acids, and phenolic compounds also contribute to the flavor of small fruit. The sensory characteristics that are most associated with small fruit are the basic taste attributes of sweetness, sourness, bitterness, astringency, and the various flavor and aroma attributes associated with volatile compounds. Consumers tend to prefer fruit that are first sweet and secondly aromatic. Cultural and individual differences may affect perception of flavor. In a study with French, American, and Vietnamese students, the word strawberry was found to be highly associated with sweet for Americans, sweet and acid for Vietnamese, and only slightly associated with sweet for French students
(Sauvageot et al., 2000). Nelson et al. (1963) noted that with grapes, individuals varied widely in their taste preferences, relative to individual tolerances of acidity and sweetness.

Some years ago, the observation was made that sugar/acid ratios could help predict fruit quality. Nelson and Richardson (1967) observed that in 'Thompson Seedless' grapes, a neutrally flavored fruit, flavor perception was primarily determined by the amount of acid relative to the amount of sugars. They noted that neither alone was a sufficient predictor of flavor quality, or maturity, but the combination of the two could be used to predict the best time to harvest a fruit showing little color change or softening. By using the simple ratio of soluble solids content to titratable acidity, grapes could be harvested at a point where flavor was acceptable to consumers but fruit was not senescent. A fruit with a low sugar and high acid ratio is usually considered sour, while fruit with a high sugar and low acid ratio is considered sweet (Table 5). High sugar/high acid ratio fruit are considered to be fruity in flavor.

The use of SSC/TA ratio as a quality predictor appears to work best in fruit with a high $(>15)$ ratio. Consumer acceptance was found to be much more predictable when the SSC/TA ratio of table grapes exceeded 22 (Nelson et al., 1963). However, the use of SSC/TA ratio appears to be most useful when fruit contain significant amounts of acid. Hypothetical values presented in Table 5 indicate that a sweet fruit may yield a ratio value double that of a fruity fruit. Guelfat-Reich and Safran (1971) found that the sugar-acid ratio as a quality predictor was very dependent on the type of grape. They found that low acid grapes were consistently rated as sweet, regardless of soluble solids content, while high acid varieties had to have a high soluble solids content to be considered tasty. This is why the soluble solids content should be given as well as the ratio when reporting on fruit quality.

In addition to the characteristic high SSC/TA ratio, strawberries also contain many unique aroma notes, and taste panel results with strawberries are often surprising. Sone et al. (2000) measured sugars, organic acids, and taste panel responses of 43 strawberry varieties. On most samples, the eating quality of a variety was judged higher when fruit had a high sugar to organic acid ratio. However, some fruit from specific varieties with a high soluble solids/titratable acidity ratio were given a low rating, indicating the importance of other qualities, such as aroma compounds, in flavor perception.

Because small fruit are complex in flavor, sensory panels that evaluate small fruit must be screened for taste acuity for sweet, sour, bitter, and astringent properties, and for character volatile notes of interest. Without proper training, panelists can often confuse the terms sourness, bitterness and astringency. Sourness is the taste stimulated by citric, malic and tartaric acids (Meilgaard et al., 1987). Astringency is a mouth-feel or tactile response, felt as dry mouth (puckering), and is caused

Table 5. Flavor characteristics related to percent sugars, acids and sugar/acid ratio in small fruit; values in parentheses represent hypothetical data (adapted from Himelrick, 1985).

Perceived flavor

Sour

Sweet

Bland

Fruity
Soluble solids (\%)

Low (3.0)

$\operatorname{High}(6.0)$

Low (3.0)

High (6.0)
Titratable acidity (\%)

High (1.0)

Low $(0.5)$

Low $(0.5)$

High (1.0)
Soluble solids/acidity
Low (3.0)

High (12.0)

Medium (6.0)

Medium (6.0) 
by polyphenols such as proanthocyanidins and esters of gallic acid and hexahyroxydiphenic acid in small fruit. In small fruit, levels of soluble polyphenols do not change with ripening. Instead, soluble pectin fragments, often de-esterified, are released during ripening (Ozawa et al., 1987), competing with tannins for binding sites on tongue receptors, and preventing the pucker response associated with immature fruit. Tannins can also cause bitterness, especially in grapes. Generally red and blue grape (Vitislabrusca) varieties contain more tannins than white/green grapes (primarily in the skin) and are perceived as being more bitter (Himelrick, 1985). Panelists can be trained on sensory characteristics by using several dilutions of the desired compounds dissolved in distilled water. Sucrose is generally used for sweetness, although fructose dissolved in water should be used in studies with high-fructose containing fruit. Citric or tartaric acid can be used for sourness, caffeine can be used for bitterness and grape juice or tea bags for astringency (Meilgaard et al., 1987). Panelists can be trained to detect certain flavor volatiles by putting the most common synthetic volatiles on cotton and placing in glass vials with stoppers. These volatiles can then be used as standards.

When conducting sensory testing with small fruit, it is difficult to provide uniform samples for testing. Pureeing will give the subjects uniform samples, but many flavor volatiles are lost or altered during the pureeing process and samples may not taste fresh. One method of evaluating fruit such as blackberries is to take a fairly large sample (i.e., 50 berries) and cut the fruit into halves or quarters and place several pieces in a cup and ask the panelists to evaluate 2 or 3 halves at a time. Replicates of each test are often done to further eliminate error.

\section{Conclusions}

Fruit quality, phytochemical content and flavor are intertwined in small fruit. Flavonoid content directly affects fruit quality through visual color and perceived astringency. Fruit with higher levels of anthocyanins may be more appealing to consumers and also have more health promoting properties. Soluble sugars and organic acids contribute indirectly to phenolic metabolism by altering $\mathrm{pH}$ and through use as building blocks for phenolic compounds, and directly enhance flavor. Not all of the health functional components of small fruit have been identified, and research indicates that a synergistic action of various compounds may provide more beneficial effects than separate actions from one or two individual components. The research area in the health functional properties of small fruit is new and additional findings will add to our knowledge and understanding of these important compounds.

\section{Literature cited}

American Heart Association. 2000. Healthy American. The new 2000 food guidelines. 7 July 2001. <www.americanheart.org/ dietaryguidelines $>$.

Anderson, J.W., B.M. Smith, and N.J. Gustafson. 1994. Health benefits and practical aspects of high-fiber diets. Amer. J. Clinical Nutr. 59:1242S-1247S.

Ballinger, W.E., E.P. Maness, and W.B. Nesbitt. 1974. A comparison of anthocyanins and wine color quality in black grapes of 39 clones of Vitis rotundifolia Micx. J. Amer. Soc. Hort. Sci. 99:338-341.

Bingham, S.A., C. Atkinson, and J. Liggins. 1998. Phytoestrogens-Where are we now? Brit. J. Nutr. 79:393-406.

Block, G., B. Patterson, and A. Subar. 1992. Fruit, vegetables, and cancer prevention: A review of the epidemiological evidence. Nutr. Cancer 18:1-29.

Brouwer, I.A., M. van Dusseldorp, C.E. West, S.Meyboom, C.M.G. Thomas, M.Duran, K.K. van het Hof, T.K.A.B. Eskes, J.G.A.J Hautvast, and R.P.M. Steegers-Theunissen. 1999. Dietary folate from vegetables and citrus fruit decreases plasma homocysteine concentrations in humans in a dietary controlled trial. J. Nutr. 129:1135-1139.

Brown, L., B. Rosner, W.W. Willett, and F.M. Sacks. 1999. Cholestrol-lowering effects of dietary fiber: A meta-analysis. Amer. J. Clinical Nutr. 69:30-42.

Buettner, G.R. 1993. The pecking order of free radicals and antioxidants: Lipid peroxidation, alpha-tocopherol, and ascorbate. Arch. Biochem. Biophysics 300:535543.

Byers, T. and N. Guerrero. 1995. Epidemiological evidence for vitamin $\mathrm{C}$ and vitamin $\mathrm{E}$ in cancer prevention. Amer. J. Clinical Nutr. 62:1385S-1392S.

Cheng, G.W. and P.J. Breen. 1991. Activity of phenylalanine ammonia-lyase (PAL) and concentrations of anthocyanins and phenolics in developing strawberry fruit. J. Amer. Soc. Hort. Sci. 116:865-869.

Costantino, L.A. Albasini, G. Rastelli, and S. Benvenuti. 1992. Activity of polyphenolic crude extracts as scavengers of superoxid radicals and inhibitors of xanthine oxidase. Planta Medica 58:342-344.

Czeizel, A.E. and I. Dudas. 1992. Prevention of the first occurrence of neural-tube defects by periconceptional vitamin supplementation. New England J. Med. 327:1832-1835.

Daniel, E.M., A.S. Kurpnick, Y.H. Heur, J.A. Blinzler, R.W. Nims, and G.D. Stoner. 1989. Extraction, stability, and quantitation of ellagic acid in various fruits and nuts. J. Food Composition Anal. 2:338-349.

Deighton, N., R. Brennan, C. Finn, and H.V. Davies. 2000. Antioxidant properties of domesticated and wild Rubus species. J. Sci. Food Agr. 80:1307-1313.

Ettinger, B., C.Y. Pak, J.T. Citron, C. Thomas, B.H. Adams, and A. Vangessel. 1997. Potassium magnesium citrate is an effective prophylaxis against recurrent calcium oxalate nephrolithiasis. J. Urol. 158:2069-2073.

Fan-Chiang. H.J. 1999. Anthocyanin pigment, nonvolatile acid and sugar composition of blackberries. MS thesis. Dept. Food Sci., Oreg. State Univ., Corvallis.

Food and Nutrition Board. 2000. Dietary reference intakes for vitamin $\mathrm{C}$, vitamin $\mathrm{E}$, selenium and carotenoids. p. 6-12. Natl. Acad. Press, Wash., D.C.

Fuleki, T. and L.J. Babjak. 1986. Natural food colorants from Ontario grapes. Highlights Agr. Res. Ont. 9:6-9.

Gey, K.F., H.B. Stahelin, and M. Eichholzer. 1993. Poor plasma status of carotene and vitamin $\mathrm{C}$ is associated with higher mortality from ischemic heart disease and stroke. Basel Prospective Study. Clin. Investigations 71:3-6.

Green, A. 1971. Soft fruits. vol. 2. p. 375410. In: A.C. Hulme (ed.). Biochemistry of fruits and their products. Academic Press, New York.

Guelfat-Reich, S. and B. Safran. 1971. Indices of maturity of table grapes as determined by variety. Amer. J. Enol. Viticult. 22:13-18.

Hertog, M.G.L., E.J.M. Feskens, P.C.H. Hollman, M.B. Katan, and D. Krombout 1993. Dietary antioxidant flavonoids and the risk of coronary heart disease: The Zutphen elderly study. Lancet 342:10071011.

Himelrick, D.G. 1985. What growers should know about Eastern varieties of table grapes, consumers like 'em. Eastern 
Grape Grower and Winery Nslt. 11:2125.

Hodges, R.E. , E.M. Baker, J. Hood, H.E. Sauberlich, and S.C. March. 1969. Experimental scurvy in man. Amer. J. Clinical Nutr. 22:535-548.

Howe, G.R., E. Benito, R. Castelleto, J. Cornee, J. Esteve, R.P. Gallagher, J.M. Iscovich, J. Deng-ao, and G.A. KaaksKune. 1992. Dietary intake of fiber and decreased risk of cancers of the colon and rectum: Evidence from the combined analysis of 13 case-contol studies. J. Natl. Cancer Inst. 84:1887-1896.

4 Hyman, J., J.A. Baron, and B.J. Dain. 1998. Dietary and supplemental calcium and the recurrence of colorectal adenomas. Cancer Epidemiol. 7:291-295.

Igarashi, K. and K. Inagaki. 1991. Effects of the major anthocyanin of wild grape (Vitis coignetiae) on serum lipid levels in rats. Agr. Biol. Chem. 55:285-287.

Jacob, R.A. 1995. The integrated antioxidant system. Nutr. Res. 15:755-766.

Jiao, H.J. and S.Y. Wang. 2000. Correlation of antioxidant capacities to oxygen radical scavenging enzyme activities in blackberry. J. Agr. Food Chem. 48:56725676.

Kader, A.A. 1992. Standardization and inspection of fresh fruits and vegetables, $\mathrm{p}$. 191-200. In: A.A. Kader (ed.). Postharvest technology. Univ. Calif. Publ. 3311.

Kalt, W., C.F. Forney, A. Martin, and R.L. Prior. 1999. Antioxidant capacity, vitamin $\mathrm{C}$, phenolics, and anthocyanins after fresh storage of small fruits. J. Agr. Food Chem. 47:4638-4644.

Kalt, W., A. Howell, C.F. Forney, and J.E. McDonald. 2001. Horticultural factors affecting antioxidant capacity of blueberries and other small fruit. HortTechnology $11(4) 523-528$.

Kalt, W., J.E. Mc Donald, R.D. Ricker, and X. Lu. 1999. Anthocyanin content and profile within and among blueberry species. Can. J. Plant Sci. 79:617-623.

Kamei, H., T. Kojima, M. Hasegawa, T. Koide, T. Umeda, T. Yukawa, and K. Terabe. 1995. Suppression of tumor cell growth by anthocyanins in vitro. Cancer Investigations 13:590-594.

Keevil, J.G., H.E. Osman, J.D. Reed, and J.D. Folts. 2000. Grape juice, but not orange juice or grapefruit juice inhibits platelet aggregation. J. Nutr. 130:53-56.

Kliewer, W., L. Howarth, and N. Omori. 1967. Concentration of tartaric acid and malic acid and their salts in Vitis vinifera grapes. Amer. J. Enol. Vitic. 18:42-54.

Krause, M.V. and L.K. Mahan. 1984. Food nutrition and diet therapy. $7^{\text {th }}$ ed. p.185. W.B. Saunders Co., Philadelphia.

Lampe, J.W. 1999. Health effects of vegetables and fruit: Assessing mechanisms of action in human experimental studies. Amer. J. Clinical Nutr. 70:475S-490S.

Lee, S.K. and A.A. Kader. 2000. Preharvest and postharvest factors influencing vitamin $\mathrm{C}$ content of horticultural crops. Postharvest Biol. Technol. 20:207-220.

Lotito, S.B. and C.G. Fraga. 2000. Catechins delay lipid oxidation and a-tocopherol and $\beta$-carotene depletion in human plasma. Proc. Soc. Expt. Biol. Med. 225:32-38.

Maas, J.L., G.J. Galletta, and G.D. Stoner. 1990. Ellagic acid, an anticarcinogen in fruits, especially in strawberries: A review. HortScience 26:10-14.

Mazur, W.M., M. Uehara, K. Wahala, and H. Adlercreutz. 2000. Phyto-oestrogen content of berries, and plasma concentrations and urinary excretion of enterolactone after a single strawberry-meal in human subjects. Brit. J. Nutr. 83:381-387.

Mazur, W. 1998. Phytoestrogen content in foods. Bailliere's Clin. Endocrinol. Metabolism 12:729-742.

Mazza, G. and E. Miniati. 1993. Anthocyanins in fruits, vegetables, and grains. p. 1-362. CRC Press, Inc., Boca Raton, Fla.

Meilgaard, M., G.V. Civille, and B.T. Carr. 1987. Sensory evaluation techniques. vol 1. p. 21-32. CRC Press, Boca Raton, Fla.

Meyer, A.S., O.S. Yi, D.A. Pearson, A.L. Waterhouse, and E.N. Frankel. 1997. Inhibition of human low-density lipoprotein oxidation in relation to composition of phenolic antioxidants in grapes (Vitis vinifera). J.Agr. Food. Chem. 45:1638-1643.

McCarron, D.A. 1997. Role of adequate dietary calcium intake in the prevention and management of salt-sensitive hypertension. Amer. J. Clin. Nutr. 65:2(suppl.)712S-716S.

Miller, N.J. and C.A. Rice-Evans. 1997. The relative contributions of ascorbic acid and phenolic antioxidants to the total antioxidant activity of orange and apple fruit juices and blackcurrant drink. Food Chem. 60:331-337.

Nelson, K.E., G.A. Baker, A.J. Winkler, M.A. Amerine, H.B. Richardson, and F.R. Jones. 1963. Chemical and sensory variability in table grapes. Hilgardia 34:1-42.

Nelson, K.E. and H.B. Richardson. 1967. Relationship between flavor and maturity in consumer acceptance of Thompson Seedless. Blue Anchor (June)23-25.

Nieves, J.W., L. Komar, F. Cosman, and R. Lindsay. 1998. Calcium potentiates the effect of estrogen and cacitonin on bone mass: Review and analysis. Amer. J. Clinical Nutr. 67:5-6.

Ozawa, T., T.H. Lilley, and E. Haslam. 1987. Polyphenol interactins: astringency and the loss of astringency in ripening fruit. Phytochemistry 26:2937-2942.

Pirie, A.J. and M.G. Mullins. 1976. Changes in anthocyanin and phenolics content of grape leaf and fruit tissues treated with sucrose, nitrate, and abscisic acid Plant Physiol. 58:468-472.

Prior, R.L., G. Cao, A. Martin, E. Sofic, J. McEwen, C. O'Brien, N. Lischner, M. Ehlenfeldt, W. Kalt, G. Krewer, and C.M. Mainland. 1998. Antioxidant capacity as influenced by total phenolic and anthocyanin content, maturity, and variety of $\mathrm{Vac}$ cinium species. J. Agr. Food. Chem. 46:2686-2693.

Sacks, F.M., W.C. Willett, A. Smith, L.E. Brown, B. Rosner, and T.J. Moore. 1998. Effect on blood pressure of potassium, calcium, and magnesium in women with low habitual intake. Hypertension 31:131138.

Sato, K., M. Nakayama, and J-I. Shigeta. 1996. Culturing conditions affecting the production of anthocyanin suspended cell cultures of strawberry. Plant Sci. 113:9198.

Sauvageot, F., D.H. Nguyen, and D. Valentin. 2000. Do words evoke taste feelings? (in French). A comparison between French, American and Vietnamese students. Sci. Aliments 20:491-522.

Slaughter, J.C. 1999. The naturally occurring furanones: formation and function from pheromone to food. Biol. Rev. 74:259-276.

Smith, M.A.L., K.A. Marley, D. Seigler, K.W. Singletary, and B. Meline. 2000. Bioactive properties of wild blueberry fruits. J. Food Sci. 65:352-356.

Sone, K., T. Mochizuki, and Y. Noguchi. 2000. Relationship between stability of eating quality of strawberry cultivars and their sugar and organic acid contents (in Japanese). J. Jpn. Soc. Hort. Sci. 69:736743.

Steinmetz, K.A. and J.D. Potter. 1996. Vegetables, fruit and cancer prevention: A review. J. Amer. Dietetics Assn. 96:10271039 .

Teissedre, P.L., E. N. Frankel, A.L. Waterhouse, H. Peleg, and J.B. German. 1996. Inhibition of in vitro human LDL oxidation by phenolic antioxidants from grapes and wines. J. Sci. Food Agr. 70:5561.

Tucker, K.L., J. Selhub, P.W. Wilson, and I.H. Rosenberg. 1996. Dietary intake pat- 
tern relates to plasma folate and homocysteine concentrations in the Framingham Heart Study. J. Nutr. 126:3025-3031.

Tucker, K.L., M.T. Hannana, H. Chen, L.A. Cupples, P.W.F. Wilson, and D.P. Kiel. 1999. Potassium, magnesium, and fruit with vegetable intakes are associated with greater bone mineral density in elderly men and women. Amer. J. Clin. Nutr. 69:727-736.

Ulrich, R. 1970. Organic acids, p. 89-115. In: A.C. Hulme (ed.). The biochemistry of fruits and their products. vol. 1. Academic Press, New York.

U.S. Department of Agriculture, Agricultural Research Service. 2001. Nutrient database for standard reference, Release 14. 15 June 2001. <www.nal.usda.gov/ fnic/foodcomp $>$.

U.S. Department of Agriculture, Department of Health and Human Services. 2000. Dietary guidelines for Americans. $5^{\text {th }} \mathrm{ed}$. Or Home and Garden Bul. 232. 13 Aug. 2001. <www.nal.usda.gov/fnic/dga>.
Wang, H., G. Cao, and R.L. Prior. 1996. Total antioxidant capacity of fruits. J. Agr. Food Chem. 44:701-705.

Wang, S.Y. and A.W. Stretch. 2001. Antioxidant capacity in cranberry is influenced by cultivar and storage temperature. J. Agr. Food Chem. 49:969-974.

Wolk, A., J.E. Manson, M.J. Sampfer, G.A. Colditz, F.B. Hu, F.E. Speizer, C.H. Hennekens, and W.C. Willett. 1999. Longterm intake of dietary fiber and decreased risk of coronary heart disease among women. J.Amer. Medical Assn. 281:19982004.

Woodward, J.R. 1972. Physical and chemical changes in developing strawberry fruits. J. Sci. Food Agr. 23:465-473.

Young, D.B., H. Hin, and R.D. McCabe. 1995. Potassium's cardiovascular protective mechanisms. Amer. J. Physiol. 268:R825-R837. 